\title{
Sphingosine 1-Phosphate in Blood: Function, Metabolism, and Fate
}

\author{
Andreas V. Thuy Christina-Maria Reimann Nasr Y. A. Hemdan Markus H. Gräler \\ From the Department of Anesthesiology and Intensive Care Medicine, Center for Sepsis Control and \\ Care (CSCC), and the Center for Molecular Biomedicine (CMB), University Hospital Jena, Germany
}

\section{Key Words}

Sphingosine kinase - S1P-lyase - Spinster homolog 2 - Serum albumin - High density lipoprotein • Endothelial cell • Erythrocyte • Receptor

\begin{abstract}
Sphingosine 1-phosphate (S1P) is a lipid metabolite and a ligand of five G protein-coupled cell surface receptors S1PR1 to S1PR5. These receptors are expressed on various cells and cell types of the immune, cardiovascular, respiratory, hepatic, reproductive, and neurologic systems, and S1P has an impact on many different pathophysiological conditions including autoimmune, cardiovascular, and neurodegenerative diseases, cancer, deafness, osteogenesis, and reproduction. While these diverse signalling properties of S1P have been extensively reviewed, the particular role of S1P in blood is still a matter of debate. Blood contains the highest S1P concentration of all body compartments, and several questions are still not sufficiently answered: Where does it come from and how is it metabolized? Why is the concentration of S1P in blood so high? Are minor changes of the high blood S1P concentrations physiologically relevant? Do blood cells and vascular endothelial cells that are constantly exposed to high blood S1P levels still respond to S1P via S1P receptors? Recent data reveal new insights into the functional role and the metabolic fate of blood-borne S1P. This review aims to summarize our current knowledge regarding the source, secretion, transportation, function, metabolism, and fate of S1P in blood.
\end{abstract}

Copyright (C) 2014 S. Karger AG, Basel

\section{Introduction}

Under normal physiological conditions the highest S1P concentration throughout the body was found in blood [1,2]. Although S1P is able to activate five cell surface receptors at 
low nanomolar concentrations [3-8], S1P concentrations in blood plasma reach about 200 $\mathrm{nM}$ in humans and $700 \mathrm{nM}$ in mice $[2,9,10]$. Much higher values may be detected if blood cells were not immediately separated from plasma, because human and mouse red blood cells (RBC) contain more than $2000 \mathrm{nM} \mathrm{S1P}$ in $1 \mathrm{x} 10 \mathrm{E} 10$ cells, resembling a hematocrit of $100 \%$ [11]. Blood plasma S1P values are therefore much higher than required for optimal S1PR stimulation. Although it was reported that differences in the plasma S1P concentration may control thymic P-selectin expression and homing of thymic T cell progenitors [12], it is not clear how such differences in high S1P concentrations that are theoretically all capable to fully activate all known S1P receptors induce different responses. A possible answer could be different receptor availability and/or signalling of S1P associated with serum albumin or lipoproteins [13]. Studies with the anti-S1P antibody Sphingomab demonstrated that antibody-captured S1P was replaced with S1P released from RBC within $24 \mathrm{~h} \mathrm{[14].} \mathrm{The} \mathrm{S1P-}$ concentration in plasma is therefore well-buffered by RBC, which should ensure quite stable values. The S1P-buffering capacity of RBC was further evidenced by the observation that anaemic patients suffer not only from a lower haematocrit, but also from lower S1P-levels in plasma compared to healthy volunteers $[9,15]$. The functional relevance of this observation is not yet clear. Here we summarize our current view on the function and metabolism of S1P in blood.

\section{Sources of blood-borne S1P}

Several candidates for the generation of S1P in blood have been identified in recent years, including RBC $[9,11,16]$, endothelial cells [17-19], thrombocytes [20, 21], mast cells $[22,23]$, and macrophages [24]. Across these cell types the primary mechanism for S1P production remains conserved. This consists primarily of hydrolysis of sphingomyelin to ceramide catalyzed by sphingomyelinases, production of sphingosine from ceramide via the action of cermidases, and further phosphorylation of sphingosine via sphingosine kinases (SphK) (Fig. 1) [11].

\section{$R B C$}

Most recent work suggests RBC as the primary source of S1P in the blood plasma compartment $[9,11,16,25]$. In addition to high SphK activities [26], RBC possess several unique features which show them to be highly adapted for this purpose. Of interest is the fact that RBC have been shown to lack the enzyme systems necessary for the degradation of S1P namely: S1P-lyase and S1P phosphohydrolase [25]. Although RBC are incapable of synthesizing the S1P precursor sphingosine from ceramide, evidence has shown that these cells also possess high levels of SphKactivities [26], and are capable of importing sphingosine from the extracellular environment [25]. Together this suggests a possible "recycling" mechanism for sphingosine [25]. Interestingly, on top of being capable of synthesizing S1P from sphingosine, $\mathrm{RBC}$ are also able to import S1P from the surrounding microenvironment and, due to the lack of degrading enzymes $[25,27]$ are well adapted to storing and protecting high concentrations of S1P (approximately 50\% of plasma S1P [25]) from degradation [11]. In contrast to thrombocytes, which evidence has shown to be only capable of releasing S1P following activation [28], RBC mediated release of S1P has been suggested to occur in a stimuli independent manner [26], although the presence of plasma is required [11] and extracellular HDL and albumin are capable of enhancing this release [11, 29]. Interestingly, the high rate of S1P generation may serve as a protective mechanism against apoptosis (in this case eryptosis). High concentrations of sphingosine, but not of S1P, have been shown to induce eryptosis. The rapid rate of sphingosine phosphorylation by SphKs may serve as a mechanism to limit the amount of sphingosine that is built up within the cell, thus protecting the cell from eryptosis [27]. Together, these data demonstrate RBC to be of vital importance for maintaining plasma S1P concentrations, and may serve to act as a "buffer system" against S1P depletion [11]. 


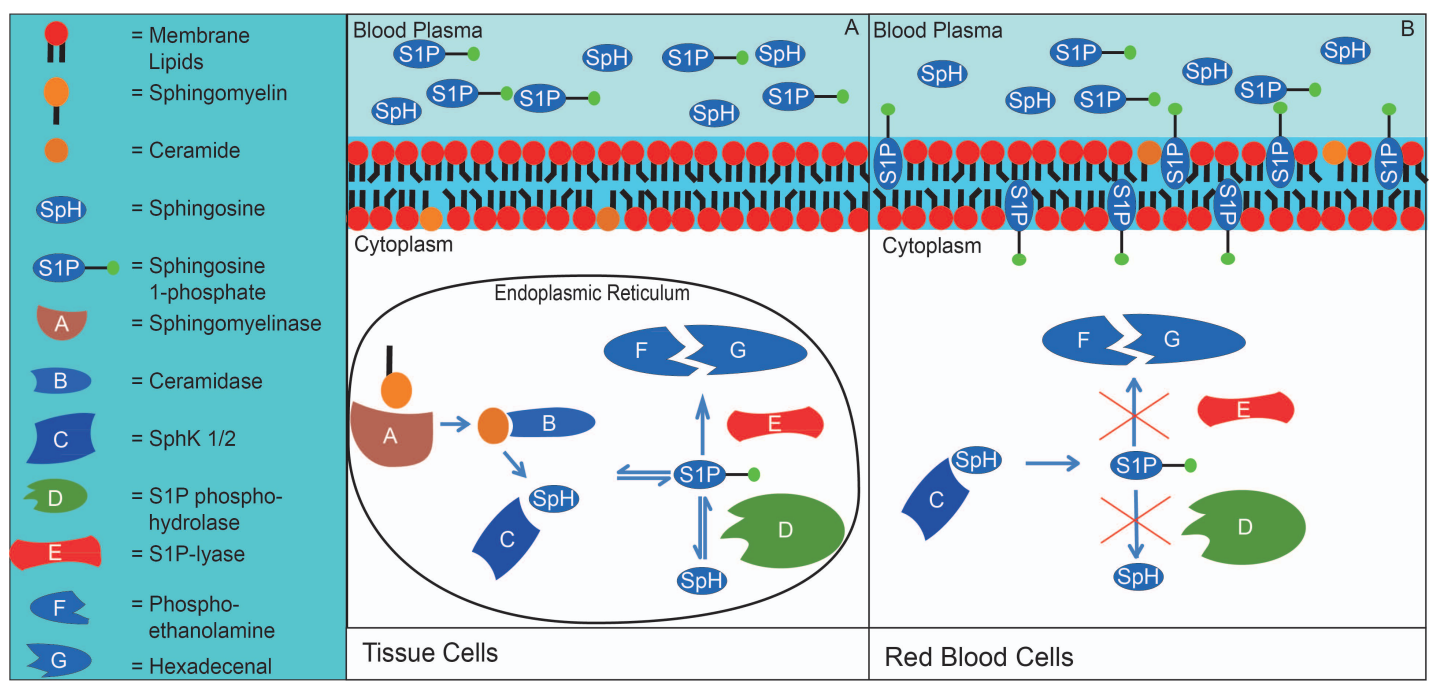

Fig. 1. A. Generalized pathway of S1P synthesis. Sphingomyelin, a major membrane component, is hydrolyzed to ceramide by sphingomyelinases. Ceramidase then deacylates ceramide to form sphingosine. Subsequently sphingosine is phosphorylated by SphK1/2 to form S1P. Cellular stores of S1P are regulated by S1P degrading enzymes, namely, S1P-lyase and S1P phosphohydrolases. While phosphohydrolases reversibly dephosphorylate S1P to sphingosine, S1P-lyase irreversibly cleaves S1P to phosphoethanolamine and hexadecenal. B. Pathway for the synthesis of S1P in RBC. RBC lack the ability to perform de novo synthesis of S1P from sphingomyelin. However, they have been shown to be capable of importing both sphingosine and S1P from the blood plasma compartment. Further, the lack of S1P degrading enzymes in these cells and their high sphingosine kinase activities make them ideally suited for the production and storage of S1P.

\section{Endothelial cells}

Most data suggest that the majority of plasma S1P is derived from RBC. Transplantation experiments with bone marrow cells derived from SphK1 ${ }^{--} \mathrm{SphK} 2^{+/-}$mice however failed to reduce the S1P concentration in blood, although SphK1 ${ }^{-/}$SphK2 ${ }^{+/-}$mice had significantly lower blood S1P levels compared to wild-type mice [18]. This result suggested an additional role of non-hematopoietic cells in maintaining S1P concentrations. Further analysis suggested endothelial cells as the principal source for non-hematopoietic derived S1P. Endothelial cells were capable of releasing S1P into the media, and sphingomyelin hydrolysis was increased in response to sheer stress with concomitant decrease of S1P degrading enzyme expression [18]. Studies with mice deficient for the protein spinster homolog 2 (Spns2), which is the predominant S1P transporter expressed in endothelial cells, suggest that endothelial cells contribute about $40 \%$ to the total pool of plasma S1P in mice [30-33]. In contrast to studies with human anemic patients having less S1P in blood than healthy volunteers [9], anemic and thrombocytopenic mice showed normal plasma S1P concentrations [18]. Interestingly, in addition to intracellular production of S1P, endothelial cells have been shown to be able to secrete SphK1 into the extracellular space [34].

\section{Thrombocytes}

Although previously identified as the primary source of S1P in the blood plasma compartment $[20,21,28]$, recently the importance of thrombocytes in this role has been called into question $[9,11,16]$. Similar to erythrocytes, thrombocytes possess several attributes which make them ideal candidates for storing and releasing S1P. Firstly, evidence has shown that thrombocytes are capable of importing extracellular sphingosine $[21,28$, 35] and efficiently phosphorylating sphingosine to S1P [28]. In addition, their relatively low S1P-lyase activity also allows for the accumulation of S1P within cells [21, 28]. Interestingly, these cells have only limited ability to perform de novo synthesis of the precursor substrates 
and are thus forced to use the membrane constituent sphingomyelin or extracellular sphingosine import [21]. Although together these attributes make thrombocytes an ideal source for physiological S1P, one major problem is the mechanism of release. In contrast to erythrocytes, thrombocytes require activation/clotting stimuli to promote release of S1P $[21,28,36]$ suggesting a minimal role in physiological S1P homeostasis.

\section{Other sources}

In addition, several other cellular sources of S1P have been identified, although the extent to which they are involved in maintaining physiological plasma S1P concentrations is limited. These include: neutrophils [26], mast cells (only in response to allergic reactions) [22], and macrophages [24]. Neutrophils and blood mononucleated cells have been shown to have a high SphK activity, and additionally have demonstrated the ability to release S1P constituently in a manner similar to RBC [26].

\section{S1P secretion and transportation}

Only recently has it been possible to find out about the mechanisms how intracellular $\mathrm{S} 1 \mathrm{P}$ is released into the blood, and what the main carrier molecules and transporters are. Several cell types have been found to secrete S1P including RBC, endothelial cells, platelets, mast cells, and neutrophils. However, the underlying mechanisms differ significantly between various cells types.

\section{Extraction of S1P from the outer RBC membrane}

$\mathrm{RBC}$ are the major source of S1P in plasma $[11,16]$. They release S1P into the plasma constitutively and do not require any stimulus [26]. Experiments using the anti-S1P antibody Sphingomab demonstrated that S1P could be extracted from RBC just by antibody binding, suggesting the presence of S1P in the outer RBC membrane [9]. Integration of fluorescentlylabelled S1P in the RBC membrane was confirmed by fluorescence microscopy, and flippaseactivating agents supported S1P-release from RBC, while flippase inhibitors negatively influenced S1P release from RBC [9]. Serum albumin and high density lipoproteins (HDL) were subsequently identified as the principal S1P-extracting molecules in plasma [9]. Stoichiometric analyses revealed that one S1P molecule was extracted by 500 serum albumin molecules, indicating that serum albumin did not physically bind S1P. Classical binding would include a specific binding site on serum albumin molecules that can be occupied by S1P and blocked by other compounds. That was not the case. Serum albumin rather supported the transition of S1P from the RBC membrane into plasma by increasing the overall solubility of S1P [9]. We call this "association with S1P" to discriminate it from the above-mentioned classical physical binding of these two molecules. The identification of apolipoprotein $\mathrm{M}$ (ApoM) as the principal binding partner of S1P in HDL [37] suggest that one S1P molecule could be extracted with one ApoM molecule, although primary data are not available to proof this assumption.

\section{Constitutive S1P release by ABC transporters}

Although the ATP-binding cassette (ABC) transporter inhibitor vanadate did not inhibit S1P-release from RBC in the above-mentioned experiments that identified extraction of S1P from the RBC membrane as the principal mechanism of S1P release from RBC [9], the transport of S1P into rat RBC inside-out membrane vesicles (IOV) was increased by the addition of ATP, dATP, and a non-hydrolysable ATP-analogue [38]. The presence of serum albumin in the extracellular medium was again necessary for this process. Vanadate inhibited the uptake of S1P in IOV, which suggested that the release of S1P by RBC was probably dependent on $A B C$ transporters [38]. Other studies however could not confirm the involvement of $A B C$ transporters in S1P release from RBC [9, 39]. 


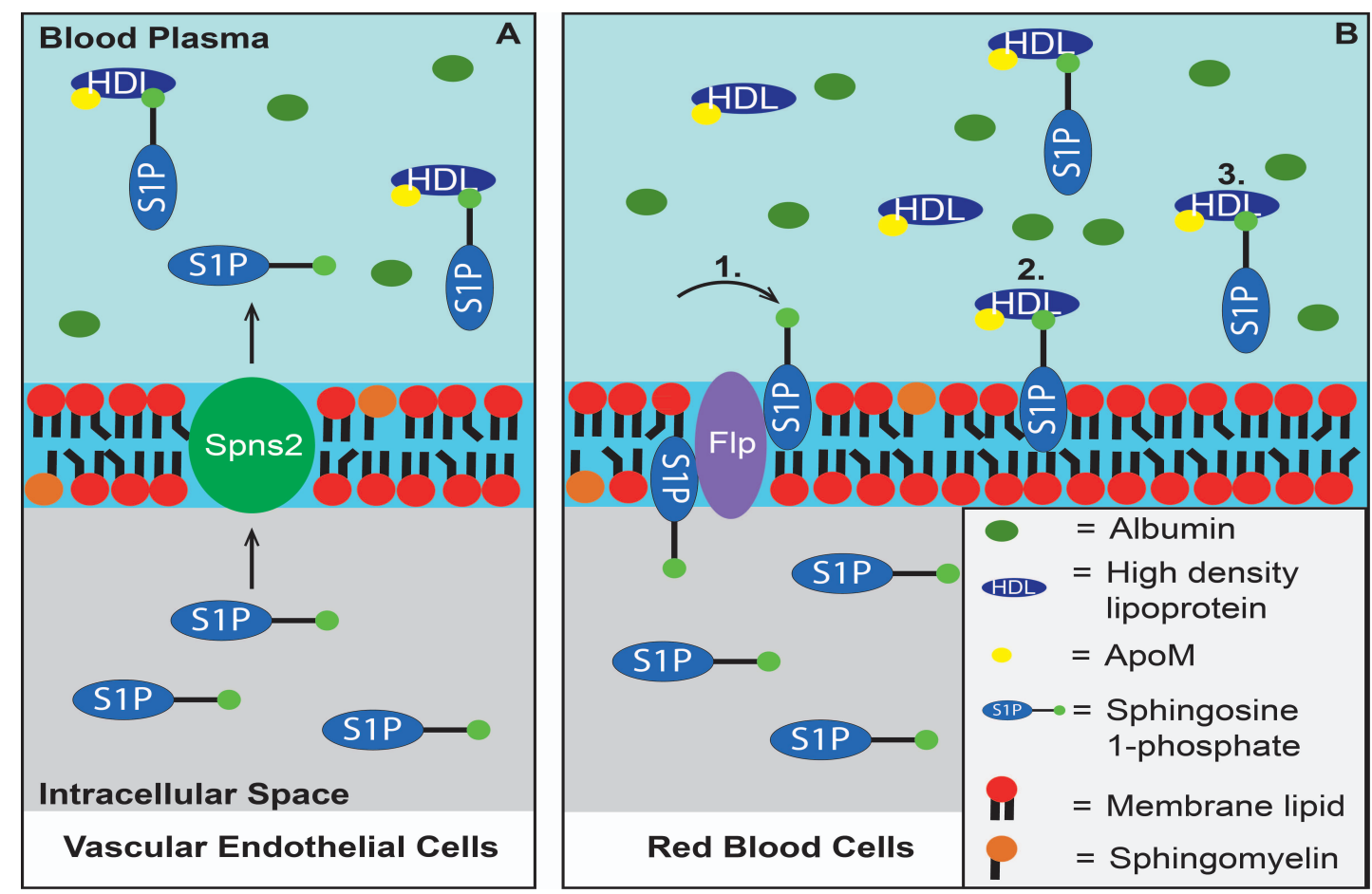

Fig. 2. Different S1P export mechanisms. A: In vascular endothelial cells, intracellular S1P is exported via Spns2. B: In RBC, S1P is translocated from the intracellular side of the membrane to the extracellular side by flippases (Flp) (1). Membrane-bound S1P is then extracted from the outer membrane by apoM rich HDL (2). In plasma, S1P is bound to apoM rich HDL (3). Serum albumin in plasma does not directly bind S1P but facilitates its release from the membrane and increases its solubility. ApoM, apolipoprotein M; Flp: flippase; HDL, high density lipoprotein; Spns2, spinster homolog 2.

\section{Induced S1P release by $A B C$ transporters}

In contrast to RBC, platelets have been found to release S1P in a stimulation-dependent manner [26]. Agents such as thrombin, collagen, $\mathrm{ADP}$, and $\mathrm{Ca}^{2+}$ showed an induction of S1P release $[28,40]$. Thrombin-induced S1P release in rat platelets was sensitive to pretreatment with the protein kinase C (PKC) inhibitor staurosporin and the putative inhibitor of ABC transporter glyburide [40]. However, $\mathrm{Ca}^{2+}$-induced S1P release could not be prevented by staurosporin or glyburide treatment, indicating two different underlying mechanisms. While thrombin-induced S1P release was ATP dependent, the $\mathrm{Ca}^{2+}$ stimulated S1P release was not [40]. Experiments with human platelets showed that thrombin-induced S1P release was mediated via thromboxane synthesis and thromboxane receptor activation [41].

Similar to platelets, mast cells also secrete S1P upon stimulation. In this cell type, antigen is able to induce S1P secretion [42]. The process is energy-dependent and can be blocked by the ABCC1 inhibitor MK571. This indicates that transporters of the ABCC1 family may be responsible for S1P secretion in mast cells [42]. However, plasma S1P levels were normal in ABCC1 knockout animals, suggesting other transport mechanisms that can compensate for ABCC1 loss [39].

\section{S1P release by Spns2}

Apart from ABC transporters, Spns2 appears to be the most important transporter for cellular S1P release, as evidenced by various knockout studies [30-33]. Zebrafish that lack Spns2 show a phenotype of spina bifida, similar to S1PR2 knockout animals [43]. In mammals, trafficking of lymphocytes is impaired upon Spns2 knockout, indicating its importance for normal immune system functionality [32]. However, in RBC and stimulated platelets of 
Spns2 knockout mice, S1P secretion is comparable to wild type (WT) mice. In these cell types Spns2 does not play a role in S1P secretion [32]. In contrast, vascular endothelial cells require Spns2 for normal S1P release [32] (Fig. 2A). In Spns2 KO mice, plasma S1P levels decrease by about $40 \%$ [32]. The remaining $60 \%$ of the original S1P level are most likely due to RBC-mediated S1P secretion. This coincides with reports identifying RBC as the main plasma S1P source [11].

Serum albumin as a carrier for S1P in blood

Early on serum albumin was recognized as a facilitator of lipid solubility [44]. It was postulated that S1P binds to serum albumin, and that S1P bound to serum albumin would increase the efficacy of S1P receptor stimulation. Current data however indicate that neither physical binding of S1P to serum albumin nor enhancement of S1P receptor signalling occurs [9]. Serum albumin is nonetheless an important plasma constituent that facilitates the solubility and accomplishes the liberation of S1P from RBC membranes [9] (Fig. 2B). Current data support the notion that serum albumin-associated S1P can be considered as its free form since it is not physically bound to serum albumin. In fact, S1P may not even have direct contact to serum albumin. The latter only seems to increase the solubility of S1P in aqueous solutions. This unbound S1P can activate S1P receptors and is fully accessible to metabolizing enzymes [9].

\section{Association of S1P with HDL}

Plasma fractionation revealed co-elution of S1P not only with serum albumin, but also with lipoproteins, particularly HDL $[1,45]$. Polyacrylamide gel electrophoresis demonstrated that more than $50 \%$ of plasma S1P was bound to HDL and about $40 \%$ was associated with albumin [45]. More recent data suggest an even higher portion of HDL-bound S1P that constitutes up to $90 \%$ of the total plasma S1P [13]. Further studies indicate that apoM, a lipocalin family member, plays an important role in plasma S1P distribution. S1P could only be detected in the apoM rich HDL fraction (Fig. 2B), while the apoM free HDL fraction was depleted of S1P [37]. The human apoM HDL complex was able to activate S1PR1, resulting in MAPK phosphorylation and Akt downstream signalling. In contrast, the apoM free HDL did not activate receptor downstream signalling [37]. Studies with mice overexpressing hepatic apoM showed that 3-5 fold higher plasma apoM levels in these mice resulted in about 5-fold increased S1P plasma levels [46]. In addition apoM in HDL probably serves as the rate-limiting factor for S1P secretion, as apoM overexpressing hepatocytes that were treated with the ceramide synthase inhibitor fumonisin B1 did not increase S1P secretion despite elevated cellular S1P levels. This further emphasizes the importance of apoM as a transporter of plasma S1P.

\section{Function of S1P in blood}

Although the role of S1P as a signalling molecule has been known for more than 2 decades, the functional relevance of S1P in blood is only slowly becoming unscrambled. Current data indicate that S1P in blood is important for various different physiological processes, including lymphocyte circulation [16], vascular integrity [47], bone homeostasis [48], neovascularization [49], and antigen presentation [50].

\section{Regulation of lymphocyte circulation}

One of the first hints that S1P may be involved in the regulation of lymphocyte circulation derived from studies with the sphingosine analogue FTY720, which inhibits lymphocyte emigration from lymph nodes [51]. Further studies revealed that FTY720 is phosphorylated mainly by SphK2 in vivo, and that the phosphate, which closely resembles S1P, is the active compound that induces lymphopenia [52, 53]. But instead of activating lymphocytes, prolonged internalization and degradation of S1PR1 in lymphocytes turned out to be the 
relevant mechanism behind lymphopenia induction [54-56]. Further studies revealed that S1PR1 is not only responsible for lymphocyte emigration from lymph nodes, but also for egress of mature thymocytes from thymus $[55,57]$. It also contributes to B cell emigration from bone marrow $[58,59]$. Inducible deletion of SphK1/2 mainly in hematopoietic and vascular endothelial cells led to complete depletion of S1P in blood, which in turn induced lymphopenia [16]. These studies demonstrate the importance of blood-borne S1P as a required exit signal for lymphocytes and thymocytes to enter circulation, although other sources of S1P like lymphatic endothelial cells for S1P in lymph [17] and pericytes for S1P in thymus [19] turned out to be important for this process as well. It was proposed that differences in the plasma S1P concentration also control thymic P-selectin expression and homing of thymic T cell progenitors [12].

\section{Maintenance of vascular integrity}

Garcia and colleagues demonstrated that S1P is an angiogenetic factor that stabilizes the endothelial cell barrier via pertussis toxin sensitive G protein-coupled receptors [60]. It was proposed that S1P released from activated thrombocytes facilitates wound healing. Depletion of S1P from blood in mice demonstrated that it was not only active in the process of wound healing, but also in the maintenance of vascular integrity [47]. S1P in blood stabilizes the barrier function of vascular endothelial cells under basal conditions and after an immune challenge. While the reduced basal barrier integrity in blood S1P depleted mice did not cause obvious physiological problems, the severely disrupted vascular endothelial barrier was generally lethal after the induction of an anaphylactic shock [47]. The mechanism by which S1P maintains vascular integrity is not quite clear yet. Enhancement of vascular barrier integrity with the S1PR1 selective agonist SEW2871 points to S1PR1 being the predominant receptor that mediates this effect [47]. But how is this signalling regulated? One obvious possibility would be the constitutive activation of S1PR1 on the luminal side of vascular endothelial cells by S1P in plasma. But high S1P concentrations present in plasma are known to desensitize S1PR1, which would prevent the proposed constant signalling. An alternative possibility would be that small amounts of plasma locally penetrate the normal vascular barrier and activate S1PR1 on the abluminal tissue-facing side. This would enhance the barrier stability again and prevent further leakage until the signalling effect is gone and small amounts of plasma are able to penetrate the barrier again, leading to another cycle of barrier enhancement [47]. This dynamic model would allow for S1PR1 desensitization by high plasma S1P concentration on the luminal side of vascular endothelial cells. The limited amount of plasma S1P that penetrates to the abluminal side would additionally explain why rather small differences in plasma S1P levels could lead to significant alterations in cellular responses. The sphingosine analogue FTY720 was also shown to inhibit vascular endothelial cell growth factor induced vascular permeability and to protect the pulmonary vascular endothelial barrier $[61,62]$. Although different pathways were suggested to participate in these effects [63-66], it could also be possible that the active compound FTY720-phosphate may be secreted to the abluminal side of vascular endothelial cells only at low concentrations. Low FTY720-phosphate concentrations increase S1PR1 stimulation due to its agonistic activity and concomitantly may avoid efficient S1PR1 desensitization that usually occurs at higher FTY720-phosphate concentrations. Further research is required to better understand the underlying mechanism that allows S1P and S1PR1 to maintain the vascular integrity.

\section{Neovascularization}

S1P not only maintains endothelial cell barrier function, but is also able to drive neovascularization. This process is an important event in tumour progression and complicates other pathologic conditions like age-related macular degeneration (AMD). The anti-S1P antibody Sphingomab inhibits neovascularization and is under clinical evaluation for treatment of both solid tumours and AMD $[49,67]$. Sphingomab was predominantly found in the plasma of treated mice, suggesting that S1P in blood could be the physiological stimulus for the observed neovascularization [49]. Similar to lymphocyte emigration and endothelial 


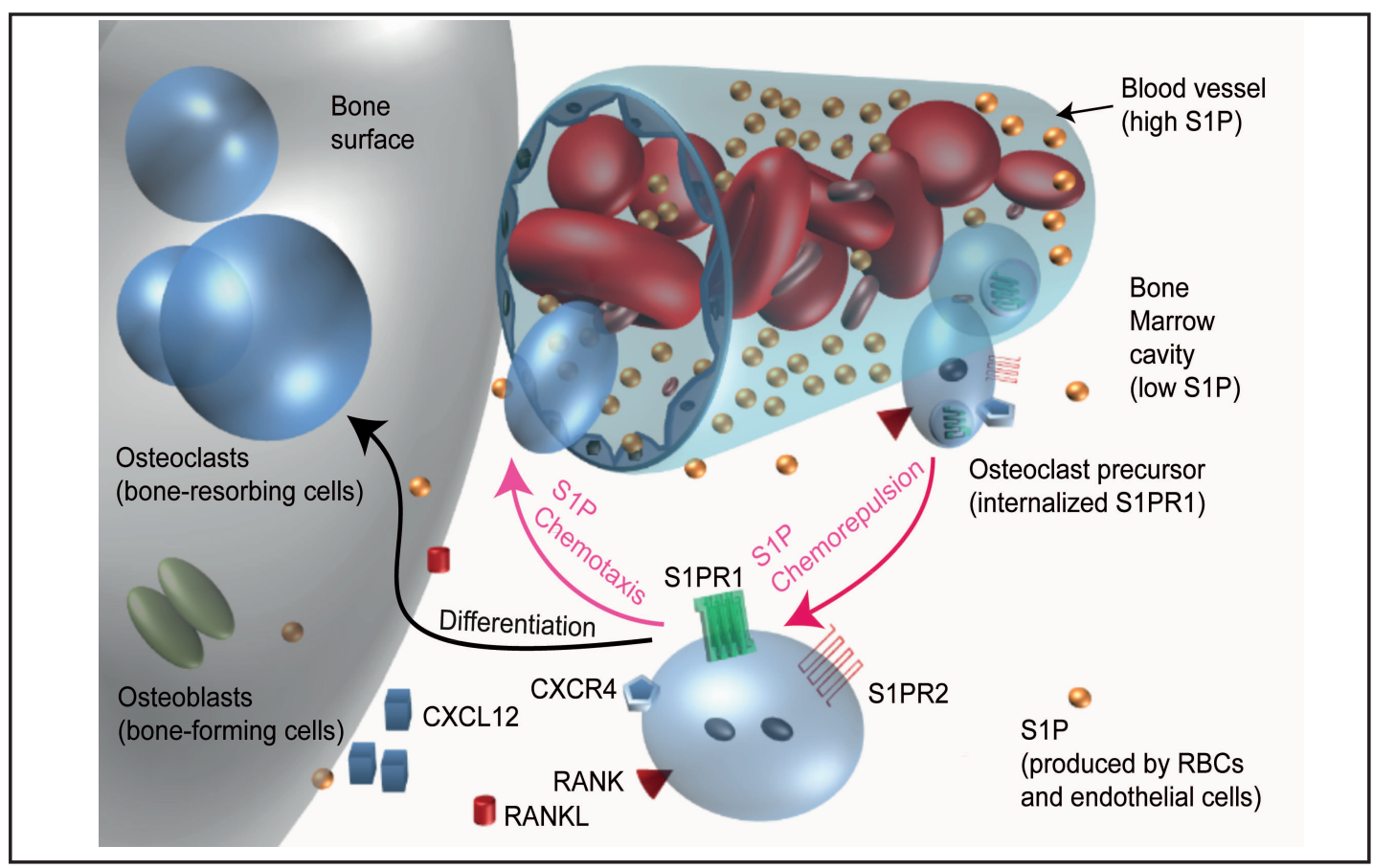

Fig. 3. S1P regulates the migration of osteoclast precursors by mediating positive (chemoattraction) and negative chemotaxis (chemorepulsion). Owing to the continuous production of S1P in blood and its degradation in peripheral tissues, an S1P-gradient is maintained. High S1P levels in circulation lead to internalization of S1PR1, rendering cells responsive to S1PR2 signaling. Therefore, osteoclast precursors move against the S1P gradient into the bone marrow cavity via chemorepulsion. Chemokines like CXCL12 attract them to bone surfaces, where they can differentiate into functional osteoclasts, or move back into circulation along the S1P gradient upon re-expression and signaling of S1PR1.

cell barrier function, S1PR1 seems to be critically involved in S1P-driven neovascularization as well $[68,69]$, although both S1PR2 and S1PR3 contribute [70, 71].

\section{Antigen presentation}

The marginal zone of the spleen is constitutively exposed to blood. Marginal zone B (MZB) cells are directed to the marginal zone via S1PR1 activation [72]. MZB cells lacking S1PR1 expression are not entering the marginal zone, but instead are directed to the B cell follicle. S1PR1 signalling overcomes chemokine signalling by CXCL13/CXCR5, which otherwise directs MZB cells into the B cell follicle [72]. It is proposed that blood S1P plays an active role in dynamically regulating MZB cell positioning by down-regulating S1PR1 surface expression on MZB cells in the marginal zone. This would enable them to follow the CXCL13 signal and to migrate to the B cell follicle. The low S1P concentration in the B cell follicle leads to re-expression of S1PR1 on the surface of MZB cells, which sensitizes them again for S1P in blood, overrides the chemokine signal CXCL13, and lets them migrate again into the marginal zone [50]. This way MZB cells are able to present blood-borne antigens to follicular dendritic cells in the B cell follicle, which can subsequently mount an immune response. Blood-borne S1P enables MZB cells to continuously migrate between the marginal zone and B cell follicles, which appears to be an important aspect of immune surveillance [73].

\section{Bone homeostasis}

Bone robustness is attained by a balance between the activity of bone-forming osteoblasts derived from osteocytes, and bone-degrading osteoclasts derived from the monocyte-macrophage hematopoietic lineage. Differentiation of both cell types is naturally 
controlled by a specific milieu of cytokines, chemokines, and growth factors including the vascular endothelial growth factor (VEGF), macrophage colony-stimulating factor (M-CSF), receptor activator of nuclear factor $\kappa$-B ligand (RANKL, a TNF family member), the chemokine CXCL12, and osteoprotegrin (OPG). S1P participates at the process of bone turnover probably via S1PR1 and S1PR2 signaling, and affects the differentiation and activity of osteoclasts by altering expression of differentiation factors as well as by regulating the circulation of osteoclast precursors between circulation and bone marrow. The latter involves S1P in blood and is based on the counteractive function of two S1P receptors, S1PR1 and S1PR2 [48, 74]. Conditional deletion of S1PR1 in the osteoclast/monocyte lineage induced osteolytic activities elicited by increased deposition of osteoclasts at bone surface, an effect that was reversed by FTY720 treatment in an ovariectomy-induced osteoporotic model [48]. Further studies suggest that S1PR1 and S1PR2 signaling exerts reciprocal regulation of osteoclast migration by mediating positive (chemoattraction) and negative chemotaxis (chemorepulsion), at low and high S1P concentrations, respectively [75]. Accordingly, S1PR2 may mediate migration of osteoclast precursors from circulation into the bone marrow cavity via chemorepulsion from S1P-rich blood into the S1P-poor bone marrow parenchyma (Fig. 3). Here, S1PR1, which has been down-regulated by high S1P levels in blood, can be re-expressed on the cell surface and may respond to blood S1P again by chemoattraction, eventually re-directing osteoclast precursors into circulation if no additional retardation signals are present [76].

While the exact mechanism of S1P in bone homeostasis is still a matter of debate, several different reports support a regulatory role of S1P in bone formation. Some of them are in agreement with the principle that $\mathrm{S} 1 \mathrm{P}$ is able to mobilize osteoclasts $[77,78]$. Others found that S1P production via SphK1 in osteoclasts and its secretion stimulates osteoblast migration and survival, which supports bone formation [79-82]. In a different study, the role of TGF-beta1 on osteoclast-mediated support of mineralization was investigated and revealed that S1P production was, however, not induced in osteoclasts upon TGF-beta1 stimulation [83]. Up-regulation of OPG and osteoblast differentiation markers upon S1P stimulation was another finding which may lead to the inhibition of osteoclast differentiation and promotion of bone formation [84]. Thereby S1P may coordinate the balance between bone formation and bone resorption. Clinical data revealed that high plasma S1P-levels were significantly associated with low bone mineral density values [85]. Furthermore systemic application of the sphingosine analogue FTY720 did not improve fracture healing in mice [86].

\section{Metabolism and fate of blood-borne S1P}

S1P in blood is mainly associated with HDL and serum albumin, both available for receptors and metabolizing enzymes, or it is stored in RBC, where it is protected from degradation [9]. Although the S1P concentration in blood is maintained at high level, several studies suggest a rather active metabolism $[18,87]$. Intravenous injection of S1P associated with serum albumin led to a rapid increase of the plasma concentration, which normalized again after 15 to 30 minutes [87]. Rapid clearance of S1P from circulation was also observed after transfusion of S1P-loaded RBC. Intravenous injection of albumin associated S1P did not result in any difference in WT and SphK2 deficient mice (Gräler et al, unpublished observation). While transfusion of C17-S1P loaded RBC revealed much higher C17-S1P levels in RBC and plasma of SphK2 deficient mice $2 \mathrm{~h}$ after injection, low to no C17-S1P levels were detected in equivalently transfused WT mice [2]. C17-S1P is one carbon atom shorter than the naturally occurring S1P and can be specifically detected and quantified by mass spectrometry [88]. SphK2 deficient mice are characterized by 3-times higher S1P levels in blood compared to WT mice [2]. The above mentioned experiments with C17-S1P loaded RBC demonstrate that SphK2 deficient mice lack efficient uptake of blood S1P by tissue cells, leading to the observed S1P accumulation in circulation. In line with this assumption, inhibition of the S1P-lyase in SphK2 deficient mice resulted in 90\% less accumulation of S1P in lymphoid tissues [2], demonstrating that blood S1P is metabolized by tissue cells via (re-) 
phosphorylation by SphK2 and final degradation by the S1P-lyase. The intriguing observation that albumin-associated S1P and S1P loaded to RBC were handled differently in circulation emphasizes the importance of the dosage form, and further discriminates RBC and albumin associated S1P. It is feasible to speculate that excess amounts of S1P associated with, but not bound to albumin, are rapidly filtered out by the liver [89], whereas S1P localized in RBC has to be maintained by regular S1P metabolism. In line with this hypothesis, application of an anti-S1P antibody resulted in increased S1P concentrations in plasma, which is caused by replacement of antibody-bound S1P with unbound S1P, both contributing to the total S1P concentration measured in plasma [14]. Co-culture experiments of RBC with endothelial cells also point to an S1P transportation based on tight RBC and endothelial cell contact, which may explain the observed differences between application of S1P associated either with albumin or with RBC [2].

\section{Concluding remarks}

Current data indicate that S1P in blood fulfils many different tasks: (1) It is integrated into the RBC membrane and thus protected from degradation, establishing a buffering system that ensures consistently high S1P levels in circulation. (2) It provides tissue cells with sphingosine, which is incorporated via phosphorylation by SphK2 and is typically degraded by the S1P-lyase. (3) It can be extracted from the RBC membrane by HDL and serum albumin, and this ensures a constant supply of receptor-available S1P for cellular signalling purposes. (4) It activates S1P receptors to regulate lymphocyte circulation, vascular integrity, neovascularization, blood-borne antigen presentation, and bone homeostasis, among others. Future studies will hopefully identify the metabolic origin, the starting point for the generation of circulatory $\mathrm{S} 1 \mathrm{P}$, which is still a missing piece in the life cycle of blood S1P.

\section{Disclosure Statement}

The authors have no conflict of interests.

\section{Acknowledgements}

This work was supported by the Deutsche Forschungsgemeinschaft (DFG), priority program 1267 "sphingolipids - signals and disease", grant GR 1943/2-2 (to M.H.G.).

\section{References}

1 Murata N, Sato K, Kon J, Tomura H, Okajima F: Quantitative measurement of sphingosine 1-phosphate by radioreceptor-binding assay. Anal Biochem 2000;282:115-120.

-2 Sensken SC, Bode C, Nagarajan M, Peest U, Pabst O, Graler MH: Redistribution of sphingosine 1-phosphate by sphingosine kinase 2 contributes to lymphopenia. J Immunol 2010;184:4133-4142.

- 3 An S, Bleu T, Huang W, Hallmark OG, Coughlin SR, Goetzl EJ: Identification of cdnas encoding two g proteincoupled receptors for lysosphingolipids. FEBS Lett 1997;417:279-282.

4 Chun J, Goetzl EJ, Hla T, Igarashi Y, Lynch KR, Moolenaar W, Pyne S, Tigyi G: International union of pharmacology. Xxxiv. Lysophospholipid receptor nomenclature. Pharmacol Rev 2002;54:265-269.

5 Chun J, Hla T, Lynch KR, Spiegel S, Moolenaar WH: International union of basic and clinical pharmacology. Lxxviii. Lysophospholipid receptor nomenclature. Pharmacol Rev 2010;62:579-587.

6 Im DS, Heise CE, Ancellin N, O'Dowd BF, Shei GJ, Heavens RP, Rigby MR, Hla T, Mandala S, McAllister G, George SR, Lynch KR: Characterization of a novel sphingosine 1-phosphate receptor, edg-8. J Biol Chem 2000;275:14281-14286.

7 Lee MJ, Van Brocklyn JR, Thangada S, Liu CH, Hand AR, Menzeleev R, Spiegel S, Hla T: Sphingosine-1phosphate as a ligand for the g protein-coupled receptor edg-1. Science 1998;279:1552-1555. 
8 Van Brocklyn JR, Gräler MH, Bernhardt G, Hobson JP, Lipp M, Spiegel S: Sphingosine-1-phosphate is a ligand for the g protein-coupled receptor edg-6. Blood 2000;95:2624-2629.

-9 Bode C, Sensken SC, Peest U, Beutel G, Thol F, Levkau B, Li Z, Bittman R, Huang T, Tölle M, van der Giet M, Gräler MH: Erythrocytes serve as a reservoir for cellular and extracellular sphingosine 1-phosphate. J Cell Biochem 2010;109:1232-1243.

10 Andréani P, Gräler MH: Comparative quantification of sphingolipids and analogs in biological samples by high-performance liquid chromatography after chloroform extraction. Anal Biochem 2006;358:239-246.

11 Hänel P, Andréani P, Gräler MH: Erythrocytes store and release sphingosine 1-phosphate in blood. FASEB J 2007;21:1202-1209.

12 Gossens K, Naus S, Corbel SY, Lin S, Rossi FM, Kast J, Ziltener HJ: Thymic progenitor homing and lymphocyte homeostasis are linked via s1p-controlled expression of thymic p-selectin/ccl25. J Exp Med 2009;206:761-778.

-13 Sattler KJ, Elbasan S, Keul P, Elter-Schulz M, Bode C, Gräler MH, Brocker-Preuss M, Budde T, Erbel R, Heusch G, Levkau B: Sphingosine 1-phosphate levels in plasma and hdl are altered in coronary artery disease. Basic Res Cardiol 2010;105:821-832.

14 Sensken SC, Nagarajan M, Bode C, Gräler MH: Local inactivation of sphingosine 1-phosphate in lymph nodes induces lymphopenia. J Immunol 2011;186:3432-3440.

15 Selim S, Sunkara M, Salous AK, Leung SW, Berdyshev EV, Bailey A, Campbell CL, Charnigo R, Morris AJ, Smyth SS: Plasma levels of sphingosine 1-phosphate are strongly correlated with haematocrit, but variably restored by red blood cell transfusions. Clin Sci (Lond) 2011;121:565-572.

16 Pappu R, Schwab SR, Cornelissen I, Pereira JP, Regard JB, Xu Y, Camerer E, Zheng YW, Huang Y, Cyster JG, Coughlin SR: Promotion of lymphocyte egress into blood and lymph by distinct sources of sphingosine-1phosphate. Science 2007;316:295-298.

17 Pham TH, Baluk P, Xu Y, Grigorova I, Bankovich AJ, Pappu R, Coughlin SR, McDonald DM, Schwab SR, Cyster JG: Lymphatic endothelial cell sphingosine kinase activity is required for lymphocyte egress and lymphatic patterning. J Exp Med 2010;207:17-27.

18 Venkataraman K, Lee YM, Michaud J, Thangada S, Ai Y, Bonkovsky HL, Parikh NS, Habrukowich C, Hla T: Vascular endothelium as a contributor of plasma sphingosine 1-phosphate. Circ Res 2008;102:669-676.

19 Zachariah MA, Cyster JG: Neural crest-derived pericytes promote egress of mature thymocytes at the corticomedullary junction. Science 2010;328:1129-1135.

20 Dahm F, Nocito A, Bielawska A, Lang KS, Georgiev P, Asmis LM, Bielawski J, Madon J, Hannun YA, Clavien PA: Distribution and dynamic changes of sphingolipids in blood in response to platelet activation. J Thromb Haemost 2006;4:2704-2709.

21 Tani M, Sano T, Ito M, Igarashi Y: Mechanisms of sphingosine and sphingosine 1-phosphate generation in human platelets. J Lipid Res 2005;46:2458-2467.

22 Jolly PS, Bektas M, Olivera A, Gonzalez-Espinosa C, Proia RL, Rivera J, Milstien S, Spiegel S: Transactivation of sphingosine-1-phosphate receptors by fcepsilonri triggering is required for normal mast cell degranulation and chemotaxis. J Exp Med 2004;199:959-970.

23 Jolly PS, Bektas M, Watterson KR, Sankala H, Payne SG, Milstien S, Spiegel S: Expression of sphk1 impairs degranulation and motility of rbl-2h3 mast cells by desensitizing s1p receptors. Blood 2005;105:47364742.

24 Xiong Y, Lee HJ, Mariko B, Lu YC, Dannenberg AJ, Haka AS, Maxfield FR, Camerer E, Proia RL, Hla T: Sphingosine kinases are not required for inflammatory responses in macrophages. J Biol Chem 2013;288:32563-32573.

25 Ito K, Anada Y, Tani M, Ikeda M, Sano T, Kihara A, Igarashi Y: Lack of sphingosine 1-phosphate-degrading enzymes in erythrocytes. Biochem Biophys Res Commun 2007;357:212-217.

26 Yang L, Yatomi Y, Miura Y, Satoh K, Ozaki Y: Metabolism and functional effects of sphingolipids in blood cells. Br J Haematol 1999;107:282-293.

27 Qadri SM, Bauer J, Zelenak C, Mahmud H, Kucherenko Y, Lee SH, Ferlinz K, Lang F: Sphingosine but not sphingosine-1-phosphate stimulates suicidal erythrocyte death. Cell Physiol Biochem 2011;28:339-346.

28 Yatomi Y, Ruan F, Hakomori S, Igarashi Y: Sphingosine-1-phosphate: A platelet-activating sphingolipid released from agonist-stimulated human platelets. Blood 1995;86:193-202.

29 Xiong SL, Liu X, Yi GH: High-density lipoprotein induces cyclooxygenase-2 expression and prostaglandin i-2 release in endothelial cells through sphingosine kinase-2. Mol Cell Biochem 2014; 389:197-207. 
-30 Mendoza A, Breart B, Ramos-Perez WD, Pitt LA, Gobert M, Sunkara M, Lafaille JJ, Morris AJ, Schwab SR: The transporter spns2 is required for secretion of lymph but not plasma sphingosine-1-phosphate. Cell Rep 2012;2:1104-1110.

-31 Hisano Y, Kobayashi N, Yamaguchi A, Nishi T: Mouse spns2 functions as a sphingosine-1-phosphate transporter in vascular endothelial cells. PLoS One 2012;7:e38941.

-32 Nijnik A, Clare S, Hale C, Chen J, Raisen C, Mottram L, Lucas M, Estabel J, Ryder E, Adissu H, Sanger Mouse Genetics P, Adams NC, Ramirez-Solis R, White JK, Steel KP, Dougan G, Hancock RE: The role of sphingosine1-phosphate transporter spns2 in immune system function. J Immunol 2012;189:102-111.

-33 Fukuhara S, Simmons S, Kawamura S, Inoue A, Orba Y, Tokudome T, Sunden Y, Arai Y, Moriwaki K, Ishida J, Uemura A, Kiyonari H, Abe T, Fukamizu A, Hirashima M, Sawa H, Aoki J, Ishii M, Mochizuki N: The sphingosine-1-phosphate transporter spns2 expressed on endothelial cells regulates lymphocyte trafficking in mice. J Clin Invest 2012;122:1416-1426.

-34 Ancellin N, Colmont C, Su J, Li Q, Mittereder N, Chae SS, Stefansson S, Liau G, Hla T: Extracellular export of sphingosine kinase-1 enzyme. Sphingosine 1-phosphate generation and the induction of angiogenic vascular maturation. J Biol Chem 2002;277:6667-6675.

35 Yatomi Y, Igarashi Y, Yang L, Hisano N, Qi R, Asazuma N, Satoh K, Ozaki Y, Kume S: Sphingosine 1-phosphate, a bioactive sphingolipid abundantly stored in platelets, is a normal constituent of human plasma and serum. J Biochem 1997;121:969-973.

-36 Knapp M, Zendzian-Piotrowska M, Blachnio-Zabielska A, Zabielski P, Kurek K, Gorski J: Myocardial infarction differentially alters sphingolipid levels in plasma, erythrocytes and platelets of the rat. Basic Res Cardiol 2012;107:294.

37 Christoffersen C, Obinata H, Kumaraswamy SB, Galvani S, Ahnstrom J, Sevvana M, Egerer-Sieber C, Muller YA, Hla T, Nielsen LB, Dahlback B: Endothelium-protective sphingosine-1-phosphate provided by hdlassociated apolipoprotein m. Proc Natl Acad Sci U S A 2011;108:9613-9618.

38 Kobayashi N, Kobayashi N, Yamaguchi A, Nishi T: Characterization of the atp-dependent sphingosine 1-phosphate transporter in rat erythrocytes. J Biol Chem 2009;284:21192-21200.

-39 Lee YM, Venkataraman K, Hwang SI, Han DK, Hla T: A novel method to quantify sphingosine 1-phosphate by immobilized metal affinity chromatography (imac). Prostaglandins Other Lipid Mediat 2007;84:154162.

40 Kobayashi N, Nishi T, Hirata T, Kihara A, Sano T, Igarashi Y, Yamaguchi A: Sphingosine 1-phosphate is released from the cytosol of rat platelets in a carrier-mediated manner. J Lipid Res 2006;47:614-621.

41 Ulrych T, Bohm A, Polzin A, Daum G, Nusing RM, Geisslinger G, Hohlfeld T, Schror K, Rauch BH: Release of sphingosine-1-phosphate from human platelets is dependent on thromboxane formation. J Thromb Haemost 2011;9:790-798.

42 Mitra P, Oskeritzian CA, Payne SG, Beaven MA, Milstien S, Spiegel S: Role of abcc1 in export of sphingosine1-phosphate from mast cells. Proc Natl Acad Sci U S A 2006;103:16394-16399.

43 Kawahara A, Nishi T, Hisano Y, Fukui H, Yamaguchi A, Mochizuki N: The sphingolipid transporter spns2 functions in migration of zebrafish myocardial precursors. Science 2009;323:524-527.

44 Lambeth JD, Burnham DN, Tyagi SR: Sphinganine effects on chemoattractant-induced diacylglycerol generation, calcium fluxes, superoxide production, and on cell viability in the human neutrophil. Delivery of sphinganine with bovine serum albumin minimizes cytotoxicity without affecting inhibition of the respiratory burst. J Biol Chem 1988;263:3818-3822.

45 Aoki S, Yatomi Y, Ohta M, Osada M, Kazama F, Satoh K, Nakahara K, Ozaki Y: Sphingosine 1-phosphaterelated metabolism in the blood vessel. J Biochem 2005;138:47-55.

46 Liu M, Seo J, Allegood J, Bi X, Zhu X, Boudyguina E, Gebre AK, Avni D, Shah D, Sorci-Thomas MG, Thomas MJ, Shelness GS, Spiegel S, Parks JS: Hepatic apolipoprotein m (apom) overexpression stimulates formation of larger apom/sphingosine 1-phosphate-enriched plasma high density lipoprotein. J Biol Chem 2014;289:2801-2814.

-47 Camerer E, Regard JB, Cornelissen I, Srinivasan Y, Duong DN, Palmer D, Pham TH, Wong JS, Pappu R, Coughlin SR: Sphingosine-1-phosphate in the plasma compartment regulates basal and inflammationinduced vascular leak in mice. J Clin Invest 2009;119:1871-1879.

-48 Ishii M, Egen JG, Klauschen F, Meier-Schellersheim M, Saeki Y, Vacher J, Proia RL, Germain RN: Sphingosine1-phosphate mobilizes osteoclast precursors and regulates bone homeostasis. Nature 2009;458:524-528. 
49 Visentin B, Vekich JA, Sibbald BJ, Cavalli AL, Moreno KM, Matteo RG, Garland WA, Lu Y, Yu S, Hall HS, Kundra V, Mills GB, Sabbadini RA: Validation of an anti-sphingosine-1-phosphate antibody as a potential therapeutic in reducing growth, invasion, and angiogenesis in multiple tumor lineages. Cancer Cell 2006;9:225-238.

50 Cinamon G, Zachariah MA, Lam OM, Foss FW Jr, Cyster JG: Follicular shuttling of marginal zone b cells facilitates antigen transport. Nat Immunol 2008;9:54-62.

51 Pinschewer DD, Ochsenbein AF, Odermatt B, Brinkmann V, Hengartner H, Zinkernagel RM: Fty720 immunosuppression impairs effector $t$ cell peripheral homing without affecting induction, expansion, and memory. J Immunol 2000;164:5761-5770.

52 Zemann B, Kinzel B, Muller M, Reuschel R, Mechtcheriakova D, Urtz N, Bornancin F, Baumruker T, Billich A: Sphingosine kinase type 2 is essential for lymphopenia induced by the immunomodulatory drug fty 720 . Blood 2006;107:1454-1458.

-53 Kharel Y, Lee S, Snyder AH, Sheasley-O'neill S L, Morris MA, Setiady Y, Zhu R, Zigler MA, Burcin TL, Ley K, Tung KS, Engelhard VH, Macdonald TL, Pearson-White S, Lynch KR: Sphingosine kinase 2 is required for modulation of lymphocyte traffic by fty720. J Biol Chem 2005;280:36865-36872.

54 Gräler MH, Goetzl EJ: The immunosuppressant fty720 down-regulates sphingosine 1-phosphate g-proteincoupled receptors. FASEB J 2004;18:551-553.

55 Matloubian M, Lo CG, Cinamon G, Lesneski MJ, Xu Y, Brinkmann V, Allende ML, Proia RL, Cyster JG: Lymphocyte egress from thymus and peripheral lymphoid organs is dependent on s1p receptor 1 . Nature 2004;427:355-360.

56 Oo ML, Thangada S, Wu MT, Liu CH, Macdonald TL, Lynch KR, Lin CY, Hla T: Immunosuppressive and anti-angiogenic sphingosine 1-phosphate receptor-1 agonists induce ubiquitinylation and proteasomal degradation of the receptor. J Biol Chem 2007;282:9082-9089.

57 Allende ML, Dreier JL, Mandala S, Proia RL: Expression of the sphingosine 1-phosphate receptor, s1p1, on t-cells controls thymic emigration. J Biol Chem 2004;279:15396-15401.

58 Allende ML, Tuymetova G, Lee BG, Bonifacino E, Wu YP, Proia RL: S1p1 receptor directs the release of immature b cells from bone marrow into blood. J Exp Med 2010;207:1113-1124.

59 Pereira JP, Xu Y, Cyster JG: A role for s1p and s1p1 in immature-b cell egress from mouse bone marrow. PLoS One 2010;5:e9277.

60 Garcia JG, Liu F, Verin AD, Birukova A, Dechert MA, Gerthoffer WT, Bamberg JR, English D: Sphingosine 1-phosphate promotes endothelial cell barrier integrity by edg-dependent cytoskeletal rearrangement. J Clin Invest 2001;108:689-701.

-61 Camp SM, Bittman R, Chiang ET, Moreno-Vinasco L, Mirzapoiazova T, Sammani S, Lu X, Sun C, Harbeck M, Roe M, Natarajan V, Garcia JG, Dudek SM: Synthetic analogs of fty720 [2-amino-2-(2-[4-octylphenyl]ethyl)1,3-propanediol] differentially regulate pulmonary vascular permeability in vivo and in vitro. J Pharmacol Exp Ther 2009;331:54-64.

62 Sanchez T, Estrada-Hernandez T, Paik JH, Wu MT, Venkataraman K, Brinkmann V, Claffey K, Hla T: Phosphorylation and action of the immunomodulator fty720 inhibits vascular endothelial cell growth factor-induced vascular permeability. J Biol Chem 2003;278:47281-47290.

63 Berdyshev EV, Gorshkova I, Skobeleva A, Bittman R, Lu X, Dudek SM, Mirzapoiazova T, Garcia JG, Natarajan V: Fty720 inhibits ceramide synthases and up-regulates dihydrosphingosine 1-phosphate formation in human lung endothelial cells. J Biol Chem 2009;284:5467-5477.

64 Dudek SM, Camp SM, Chiang ET, Singleton PA, Usatyuk PV, Zhao Y, Natarajan V, Garcia JG: Pulmonary endothelial cell barrier enhancement by fty720 does not require the s1p1 receptor. Cell Signal 2007;19:1754-1764.

65 Wang L, Chiang ET, Simmons JT, Garcia JG, Dudek SM: Fty720-induced human pulmonary endothelial barrier enhancement is mediated by c-abl. Eur Respir J 2011;38:78-88.

66 Wang L, Sammani S, Moreno-Vinasco L, Letsiou E, Wang T, Camp SM, Bittman R, Garcia JG, Dudek SM: Fty720 (s)-phosphonate preserves sphingosine 1-phosphate receptor 1 expression and exhibits superior barrier protection to fty720 in acute lung injury. Crit Care Med 2014;42:e189-199.

67 Caballero S, Swaney J, Moreno K, Afzal A, Kielczewski J, Stoller G, Cavalli A, Garland W, Hansen G, Sabbadini R, Grant MB: Anti-sphingosine-1-phosphate monoclonal antibodies inhibit angiogenesis and sub-retinal fibrosis in a murine model of laser-induced choroidal neovascularization. Exp Eye Res 2009;88:367-377.

68 Chae SS, Paik JH, Furneaux H, Hla T: Requirement for sphingosine 1-phosphate receptor-1 in tumor angiogenesis demonstrated by in vivo rna interference. J Clin Invest 2004;114:1082-1089. 
Thuy et al.: Signalling and Metabolism of S1P in Blood

69 LaMontagne K, Littlewood-Evans A, Schnell C, O'Reilly T, Wyder L, Sanchez T, Probst B, Butler J, Wood A, Liau G, Billy E, Theuer A, Hla T, Wood J: Antagonism of sphingosine-1-phosphate receptors by fty720 inhibits angiogenesis and tumor vascularization. Cancer Res 2006;66:221-231.

-70 Kono M, Mi Y, Liu Y, Sasaki T, Allende ML, Wu YP, Yamashita T, Proia RL: The sphingosine-1-phosphate receptors s1p1, s1p2, and s1p3 function coordinately during embryonic angiogenesis. J Biol Chem 2004;279:29367-29373.

71 Skoura A, Sanchez T, Claffey K, Mandala SM, Proia RL, Hla T: Essential role of sphingosine 1-phosphate receptor 2 in pathological angiogenesis of the mouse retina. J Clin Invest 2007;117:2506-2516.

72 Cinamon G, Matloubian M, Lesneski MJ, Xu Y, Low C, Lu T, Proia RL, Cyster JG: Sphingosine 1-phosphate receptor 1 promotes b cell localization in the splenic marginal zone. Nat Immunol 2004;5:713-720.

73 Arnon TI, Horton RM, Grigorova IL, Cyster JG: Visualization of splenic marginal zone b-cell shuttling and follicular b-cell egress. Nature 2013;493:684-688.

-74 Okamoto H, Takuwa N, Yokomizo T, Sugimoto N, Sakurada S, Shigematsu H, Takuwa Y: Inhibitory regulation of rac activation, membrane ruffling, and cell migration by the g protein-coupled sphingosine-1-phosphate receptor edg5 but not edg1 or edg3. Mol Cell Biol 2000;20:9247-9261.

-75 Ishii M, Kikuta J, Shimazu Y, Meier-Schellersheim M, Germain RN: Chemorepulsion by blood s1p regulates osteoclast precursor mobilization and bone remodeling in vivo. J Exp Med 2010;207:2793-2798.

76 Ishii T, Kawamura S, Nishiyama I, Kikuta J, Ishii M: Use of intravital microscopy and in vitro chemotaxis assays to study the roles of sphingosine-1-phosphate in bone homeostasis. Methods Mol Biol 2012;874:129-139.

77 Tanaka K, Hashizume M, Mihara M, Yoshida H, Suzuki M, Matsumoto Y: Anti-interleukin-6 receptor antibody prevents systemic bone mass loss via reducing the number of osteoclast precursors in bone marrow in a collagen-induced arthritis model. Clin Exp Immunol 2014;175:172-180.

78 Kikuta J, Kawamura S, Okiji F, Shirazaki M, Sakai S, Saito H, Ishii M: Sphingosine-1-phosphate-mediated osteoclast precursor monocyte migration is a critical point of control in antibone-resorptive action of active vitamin d. Proc Natl Acad Sci U S A 2013;110:7009-7013.

79 Quint P, Ruan M, Pederson L, Kassem M, Westendorf JJ, Khosla S, Oursler MJ: Sphingosine 1-phosphate (s1p) receptors 1 and 2 coordinately induce mesenchymal cell migration through $\mathrm{s} 1 \mathrm{p}$ activation of complementary kinase pathways. J Biol Chem 2013;288:5398-5406.

-80 Pederson L, Ruan M, Westendorf JJ, Khosla S, Oursler MJ: Regulation of bone formation by osteoclasts involves wnt/bmp signaling and the chemokine sphingosine-1-phosphate. Proc Natl Acad Sci U S A 2008;105:20764-20769.

81 Ryu J, Kim HJ, Chang EJ, Huang H, Banno Y, Kim HH: Sphingosine 1-phosphate as a regulator of osteoclast differentiation and osteoclast-osteoblast coupling. EMBO J 2006;25:5840-5851.

82 Lotinun S, Kiviranta R, Matsubara T, Alzate JA, Neff L, Luth A, Koskivirta I, Kleuser B, Vacher J, Vuorio E, Horne WC, Baron R: Osteoclast-specific cathepsin k deletion stimulates s1p-dependent bone formation. J Clin Invest 2013;123:666-681.

83 Ota K, Quint P, Ruan M, Pederson L, Westendorf JJ, Khosla S, Oursler MJ: Tgf-beta induces wnt10b in osteoclasts from female mice to enhance coupling to osteoblasts. Endocrinology 2013;154:3745-3752.

-84 Matsuzaki E, Hiratsuka S, Hamachi T, Takahashi-Yanaga F, Hashimoto Y, Higashi K, Kobayashi M, Hirofuji T, Hirata M, Maeda K: Sphingosine-1-phosphate promotes the nuclear translocation of beta-catenin and thereby induces osteoprotegerin gene expression in osteoblast-like cell lines. Bone 2013;55:315-324.

85 Lee SH, Lee SY, Lee YS, Kim BJ, Lim KH, Cho EH, Kim SW, Koh JM, Kim GS: Higher circulating sphingosine 1-phosphate levels are associated with lower bone mineral density and higher bone resorption marker in humans. J Clin Endocrinol Metab 2012;97:E1421-1428.

-86 Heilmann A, Schinke T, Bindl R, Wehner T, Rapp A, Haffner-Luntzer M, Liedert A, Amling M, Ignatius A: Systemic treatment with the sphingosine-1-phosphate analog fty720 does not improve fracture healing in mice. J Orthop Res 2013;31:1845-1850.

87 Peest U, Sensken SC, Andréani P, Hänel P, Van Veldhoven PP, Gräler MH: S1p-lyase independent clearance of extracellular sphingosine 1-phosphate after dephosphorylation and cellular uptake. J Cell Biochem 2008;104:756-772.

-88 Bode C, Gräler MH: Quantification of sphingosine-1-phosphate and related sphingolipids by liquid chromatography coupled to tandem mass spectrometry. Methods Mol Biol 2012;874:33-44.

89 Salous AK, Panchatcharam M, Sunkara M, Mueller P, Dong A, Wang Y, Graf GA, Smyth SS, Morris AJ: Mechanism of rapid elimination of lysophosphatidic acid and related lipids from the circulation of mice. J Lipid Res 2013;54:2775-2784. 